\title{
Thanks to literature and fellow scientists
}

\author{
Albert J. DIJKSTRA \\ Carbougnères, \\ 47210 Saint-Eutrope-de-Born, France \\ <albert@dijkstra-tucker.be>
}

\begin{abstract}
Formal training has the disadvantage that trainees may simply accept what they are taught without questioning it, unlike the autodidact who can only learn by asking questions all the time. Sometimes, he will not get an answer and that need not be because the question is stupid, but may be because his peers are used to there being no satisfactory answer and have simply accepted the conventional mythology without further question. So it is about time to ask some assorted questions and where possible, suggest how to find an answer: 1) Why does the composition of the solvent used to extract oil from oilseeds affect the amount of oil being extracted and its phosphatide content? 2) Why does a heat treatment (Alcon, Exergy, expander) increase the phosphatide content of the crude oil and decrease its non-hydratable phosphatide (NHP) content? 3) Why does water degumming of crude oil remove relatively more magnesium than calcium? 4) What is the mechanism of phosphatide removal by silica hydrogel and why is it enhanced by simultaneous soap removal? 5) What is the mechanism of NHP-removal during alkali neutralisation? 6) Could it be that the Long Mix neutralisation process as used in the US leads to insufficient removal of the pro-oxidants copper and iron and that this explains why oil tends to less stable in the US than in Europe, especially when it contains linolenic acid? 7) Could different deodorisation conditions explain this geographically determined anomaly? 8) What happens during flavour reversion? 9) Why is walnut oil more stable in the nut than in the bottle? 10) How much oil is lost by saponification or hydrolysis during refining? 11) What is the mechanism of colour fixation? 12) Does the activity of interesterification catalysts depend on their counter cation? 13) What is the chemical nature of the colour formed on interesterification catalyst activation? 14) What is crystal memory? Does it exist? However, we should not forget the Dutch proverb that: "One fool can ask more questions than ten wise men can answer." On the other hand, exposing myths is half the fun and asking the right question often provides half the answer.
\end{abstract}

Key words: crystallisation; degumming, edible oil processing, extraction, interesterification, oil modification
The above abstract of my 2009 Chevreul Award Address has first been published on the website (www.eurofedlipid.org) announcing the $7^{\text {th }}$ EuroFedLipid Congress in Graz, Austria and subsequently, it has been included in the abstracts on the memory stick provided to each registrant of the congress. At that time, the title of the abstract was still "Questions that no one is asking" and that is also the title of the Address I presented on 20 October 2009. Having been asked to submit this Address in manuscript form for publication in this Journal, I decided to change the title to "Thanks to literature and fellow scientists" ${ }^{\prime 1}$ because I think that title more truly reflects my presentation.

\footnotetext{
* AFECG Chevreul Medal Lecture, said inside the $7^{\text {th }}$ Euro Fed Lipid Congress, Graz, Austria, 17 September 2009.

${ }^{1}$ In English, this title has a double meaning. It can therefore be translated into French as: "Grâce à la littérature et mes confrères scientifiques" and "Un grand merci pour la littérature et mes confrères scientifiques".
}

In this presentation, I discussed a number of topics related to edible oil processing (oil milling, oil refining and modification) that somehow or other struck me as being insufficiently clear and/or raised questions requiring an answer. The choice of topics was entirely my own and it therefore does not reflect any order of scientific or economic importance; it just illustrates the vagaries of an inquisitive mind. Being a chemist myself, I concentrated on the chemical aspects of these questions and if I could think of a possible answer, I suggested and discussed it. Often no possible answer presented itself and then, I had to leave it at that.

Some of the topics originate from my own observations made when I was directly involved in edible oils processing as $R$ \& $D$ director of the Vandemoortele Group in Belgium. Others originate from studying the oils and fats literature when preparing articles for scientific journals or chapters in books such as the $3^{\text {rd }}$ edition of The Lipid Handbook in which I refer to more than 1000 journal articles and patents. Hence my wish to stress the importance of the scientific literature and reflect this in the title of this paper.

\section{Phosphatide behaviour during oil milling, degumming and neutralisation}

It is more than 50 years ago that Desnuelle et al. (1951) noted that the nature of an extraction solvent affects not only the oil yield but also the phosphorus content of the extracted oil in particular. They obtained the highest phosphorus content when using the Bollmann solvent, which consists of equal parts of petroleum ether, benzene and alcohol. If this is set at $100 \%$, using petroleum ether with a boiling range of 60 to $80{ }^{\circ} \mathrm{C}$ gives a phosphorus yield of only some $15 \%$ for soya beans with a water content of $10.2 \%$, and this figure decreases to about $12 \%$ when the beans are dried before being extracted. When the soya beans (broken beans or flakes) are steam treated in an auto- 
clave before being extracted, the phosphorus yield increases to $35 \%$. The authors made similar observations for high erucic acid rapeseed and linseed but provided no explanation for these observations. material have been incorporated in the Alcon ${ }^{\circledR}$ process (Kock, 1981; Penk, 1985) for soya beans and the Super Expro or Exergy ${ }^{\circledR}$ process (Dahlén, 1998, 2000) for rapeseed. Both processes lead to an increase in the phosphorus content of the oil; a similar increase has also been observed when soya beans are treated in an expander (Rittner, 1984) before being extracted (Zhang et al., 1994). However, not only do the various heat treatments lead to more phosphatides being extracted, they also cause the amount of non-hydratable phosphatides (NHPs) to decrease. Water degumming oil obtained from seeds that have undergone a heat treatment leads to a lower residual phosphorus content.

The reason why is far from clear. NHPs consist mainly of calcium and magnesium salts of phosphatidic acid (PA) and why or how would a heat treatment of the seeds or flakes affect their concentration? After my presentation, a member of the audience pointed out to me that no PA is present in untreated beans. The PA must therefore have been formed during the treatment preceding the oil extraction and it must have been formed by phospholipase D catalysed hydrolysis. In this context, the late Katalin (Kővári), to whose memory the processing sessions of the $7^{\text {th }}$ EuroFedLipid Congress have been dedicated, described in her Chevreul
On an industrial scale, heat treatments of seed

Award Address (Kővári, 2004) the temperature range of 40 to $70^{\circ} \mathrm{C}$, where enzymes are active, as a critical process zone that should be passed through as quickly as possible to minimise NHP and FFA formation. Enzyme inactivation has also been mentioned by the Alcon ${ }^{\circledR}$ inventor (Kock, 1983) because the extraction temperature was found to have a large effect on the residual phosphorus content of his water degummed oil. Inactivation of phospholipase D would prevent PA from being formed and thus lead to a lower residual phosphorus content in the oil. On the other hand, PA formed by this hydrolysis can also be a good thing since it reduces the creaming tendency of soy milk, a tendency that can be eliminated by a controlled heat treatment of the soya beans used in the milk (I. Debruyne, personal communication).

However, using the analytical data for soy lecithin given in [9] and those for the NHP given in (Dijkstra and Van Opstal, 1989) and assuming that the crude reference oil contained $850 \mathrm{ppm}$ $\mathrm{P}$, which figure is reduced to $150 \mathrm{ppm} \mathrm{P}$ on water degumming, I could arrive at table 1. This table shows that Alcon ${ }^{\circledR}$ oil contains slightly more PA than the reference oil, 270 ppm vs 240 ppm. It therefore looks as if the Alcon ${ }^{\circledR}$ and similar heat treatments do not avoid PA formation but instead avoid the conversion of the hydratable form of PA (its potassium salt?) to the non-hydratable calcium and magnesium salts of PA but the mechanism of this conversion is anybody's guess. In addition, the heat treatments also increase the extractability of phosphatides but again, the mechanism is not known.

Table 1. Phosphatide contents of Alcon ${ }^{\circledR}$ oil (Kock, 1983) and reference soya bean oil (Dijkstra and Van Opstal, 1989).

\begin{tabular}{|c|c|c|c|c|c|c|}
\hline & \multicolumn{2}{|c|}{ Alcon ${ }^{\circledR}$ oil } & \multicolumn{4}{|c|}{ Reference oil } \\
\hline & \multirow[b]{2}{*}{$\%$} & Total & \multicolumn{2}{|c|}{ Lecithin } & \multirow{2}{*}{$\frac{\text { NHP }}{\text { ppm P }}$} & \multirow{2}{*}{$\begin{array}{l}\text { Total } \\
\text { ppm P }\end{array}$} \\
\hline & & ppm P & $\%$ & ppm P & & \\
\hline PC & 46 & 640 & 33 & 240 & & 240 \\
\hline PE & 23 & 320 & 30 & 210 & 30 & 240 \\
\hline LPC & 2 & 30 & 2 & 10 & & 10 \\
\hline PI & 8 & 110 & 14 & 100 & & 100 \\
\hline PA & 19 & 270 & 17 & 120 & 120 & 240 \\
\hline Others & 2 & 30 & 4 & 20 & & 30 \\
\hline Total & 100 & 1400 & 100 & 700 & 150 & 850 \\
\hline
\end{tabular}

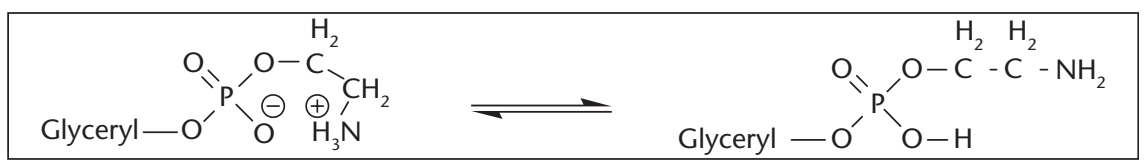

Figure 1. Equilibrium between Zwitterion and the molecule without charges.

It is not known either why phosphatidyl ethanolamine (PE) is only partially hydratable. Several authors describe NHP as Ca and Mg salts of PA and PE (Segers, 1979) but in my opinion they should be described as $\mathrm{Ca}$ and $\mathrm{Mg}$ salts of PA and some free PE. I base this opinion on literature data mentioning $\mathrm{Ca}, \mathrm{Mg}$ and $\mathrm{P}$ contents of water degummed oil. These data show that on an atomic basis, $(\mathrm{Ca}+\mathrm{Mg}) / \mathrm{P}$ is always less than unity and a fairly obvious way of explaining this inequality is by assuming that the $P E$ is free. Besides, if PE were to occur as a Ca salt, this salt would have a double positive charge at $\mathrm{pH}<9$ and would therefore be highly likely to be hydratable. Free PE is likely to occur as a Zwitterion and unlike phosphatidyl choline (PC) with its bulky methyl groups, this Zwitterion can form an internal salt with a six-atom ring structure. Because of its charges is likely to be hydratable but an equilibrium between this Zwitterion and the molecule without charges according to figure 1 should not be impossible. In that instance, the Zwitterion would be removed on water degumming leaving the molecule without charges in the oil. Further Zwitterions would then be formed so that on subsequent water degumming, further PE would be removed (Kanamoto et al., 1981). However, this is just speculation on my part.

The literature does not explain how NHP are removed during alkali refining. They certainly are, as demonstrated by Hvolby (1971) from whose publication an adapted table is shown below as table 2. But what is the mechanism? Could it be that at high $\mathrm{pH}$, a hydroxyl ion attaches itself to either the calcium ion present in the calcium phosphatidate or to the phosphorus atom of this salt according to figure 2 .

Both attachments would lead to a charged phosphatide that can be assumed to be hydratable. Accordingly, the Long Mix neutralisation process as used in the US and to a lesser extent in South America leads to low residual calcium and magnesium levels (Hvolby, 1971) but does it also lead to low residual iron and

Table 2. Removal of calcium, magnesium and phosphorus as function of $\mathrm{pH}$ (Adapted from (Hvolby, 1971)).

\begin{tabular}{|llll|}
\hline $\mathbf{p H}$ & $\mathbf{P}(\mathbf{p p m})$ & $\mathbf{C a}(\mathbf{p p m})$ & $\mathbf{M g}(\mathbf{p p m})$ \\
\hline 8 & 4.18 & 1.25 & 2.08 \\
\hline 9 & 3.83 & 1.33 & 2.16 \\
\hline 10 & 2.55 & 1.02 & 1.54 \\
\hline 11 & 2.00 & 0.79 & 1.37 \\
\hline 12 & 1.83 & 0.71 & 1.07 \\
\hline 13 & 1.11 & 0.42 & 0.66 \\
\hline 14 & 0.00 & 0.00 & 0.00 \\
\hline
\end{tabular}




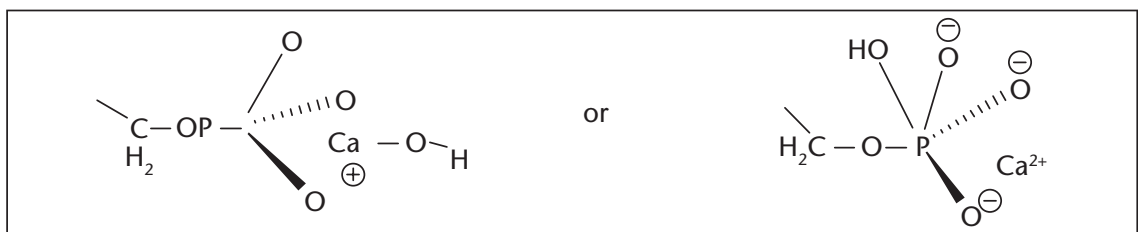

Figure 2. The two forms of attachments which would lead to a charged phosphatide.

copper levels? After all, attaining low levels for these pro-oxidative metals is a prerequisite for oil stability.

Quite some time ago, E. Deffense asked me the following question: Why is it that water degumming removes relatively more magnesium than calcium? A possible reason why we probably do not know the answer to this question is that oil analysis is limited to measuring individual elements like $\mathrm{P}, \mathrm{Ca}, \mathrm{Mg}$ and $\mathrm{Fe}$ and determining phosphatide compositions. We do not measure the concentration of their salts. If we were to develop a method to measure these salts, it might help us to generate the insight on the basis of which we could develop an oilseed pre-treatment that would avoid the formation of NHP. Such oils would only require water degumming and bleaching before being steam refined, which would be a much cheaper process producing less effluent than current processes. Perhaps this insight might also allow us to control the lecithin composition and to develop novel and more efficient equipment.

We all know that avoiding mechanical breakdowns in oil mills is of the utmost importance, and that is probably why current processes have been designed by mechanical engineers rather than chemists. Moreover, the chemical research on the extraction process that has been carried out and reported in the literature is quite old. New analytical tools have become available since then that like enzymes, might enable us to develop novel and improved processes.

Accordingly, a whole list of arguments can be compiled in favour of carrying out research aimed at developing such novel and improved processes. This list may easily convince MBAs in charge of oil mills and government officials to fund such research but in my opinion, they do not justify such research. In this context, I like to quote François Jacob, a French Nobel prize winner (Jacob, 1982) who wrote:

"The capacity to judge what problems are ripe for analysis, to decide when it is useful to reinvestigate old territory, to re-examine questions that once were considered as solved or insoluble, remains one of the most important qualities of a scientist. Creativity in science often corresponds to sure judgment in this domain."
Deciding to carry out a certain research project requires more than a list of favourable arguments. It also requires a chemist who has a hunch $^{2}$ about how to tackle the project and who believes in it. Although prevalent with the powers that be, the idea that chemists are interchangeable is a fallacy.

Phosphatides are not only removed by hydration, they can also be removed by adsorption. In the dry degumming process for instance (Sullivan, 1978) oil is treated with a strong acid such as phosphoric acid to decompose the NHP so that PA is formed. But what is the mechanism of PA adsorption on bleaching earth? Often, the bleaching earth has been acid activated, which decreases its affinity for acid compounds, the presence of degumming acid causes the PA to be non-dissociated and the degumming acid also has to be adsorbed onto the earth causing a competition with the PA. It works, but how?

As mentioned by Deffense in his Chevreul Award Address (Deffense, 2009), most Malaysian plants tended to neutralise the excess of phosphoric acid by adding calcium carbonate to protect their equipment against corrosion. In doing so they allowed the PA to react with the carbonate and form NHP again. Similarly, neutralising the excess of phosphoric acid with magnesium oxide in (Dijkstra and Van Opstal, 1989) leads to the formation of the magnesium salt of PA and when this oil is then bleached and physically refined it is quite stable despite its phosphorus content of $73 \mathrm{ppm}$. The reason for this stability is that the phosphoric acid treatment reduced the iron content of the water degummed oil from 0.88 ppm to only 0.14 ppm and, as shown subsequently (Cleenewerck and Dijkstra, 1992) the iron content of refined oil is strongly correlated with its stability, the subject of the next section.

\section{Oil stability}

I have already mentioned oil stability - or the possible lack of it - when raising the question of to what extent the Long Mix neutralisation pro-

\footnotetext{
${ }^{2}$ According to the Oxford English Dictionary, a "hunch" is "a feeling or guess based on intuition rather than fact".
}

cess removes pro-oxidative metals like iron and copper. The fact is that refined, bleached and deodorised oil in the US tends to be far less stable than in Europe. The Americans themselves blame the presence of linolenic acid for this lack of stability. Accordingly, they tended to avoid the presence of liquid soya bean oil in margarine fat blends by partially hydrogenating the entire blend and thereby eliminating its linolenic acid; they produce salad oil by winterising brush hydrogenated soya bean oil to reduce its linolenic acid content, whereas in Europe, we use the oil as such; they carried out a lot of research to develop hydrogenation catalysts with a high linolenic acid selectivity; plant breeding was used to arrive at soya bean cultivars with a lower linolenic acid content and now genetic modification has actually achieved this.

However, linolenic acid is only slightly less stable than linoleic acid as shown in table 3. According to Frankel (2005) linolenic acid with two bis-allylic carbon atoms oxidises about twice as fast as linoleic acid, which has only one bis-allylic carbon atom. Fatty acids with more methylene interrupted double bonds and thus more bis-allylic carbon atoms oxidise even faster. My figures (Dijkstra et al., 1996) are somewhat different but we agree that the difference between polyunsaturated fatty acids on the one hand and monounsaturated and saturated fatty acids on the other hand is what counts.

On the other hand, we should not forget that triglyceride oils can be remarkably stable. At home, I have two walnut trees and each year I harvest my nuts. This is a highly educational exercise since it shows that amount and quality of agricultural produce can vary quite considerably from year to year. After harvesting, I dry these nuts on wire screens ${ }^{3}$ and then store the dry nuts in the cellar. That they can be dried shows that the nutshells are permeable to gases and thus to oxygen. Nevertheless, the nuts do not taste rancid after having been stored for more than a year. The oil in the nuts does not noticeably oxidise despite the high linolenic acid content of walnut oil.

Compare this with a deodorisation experiment on soya bean oil (D. Meert, personal communication) in which the oil was deodorised for a long time at a very deep vacuum as produced by a mechanical vacuum pump. The quality control department was lyrical about this oil. It was the blandest oil they had ever tasted. Next day, the leftovers in the beakers used to

\footnotetext{
${ }^{3}$ In France, I live in the département Lot-et-Garonne (47) and this is well known for its prunes. I obtained some wire screen trays used for plum drying and use these for drying my walnuts and hazelnuts.
} 
Table 3. Relative oxidation rates of various fatty acids (rate of C18:1 equals 1.0).

\begin{tabular}{|lcc|}
\hline Fatty Acid & According to Frankel (2005) & According to Dijkstra et al. (1996) \\
\hline C18:0 & & 0.7 \\
\hline C18:1 & 1.0 & 1.0 \\
\hline C18:2 & 41 & 130 \\
\hline C18:3 & 98 & 138 \\
\hline C20:4 & 140 & \\
\hline C22:6 & 225 & \\
\hline
\end{tabular}

taste the oil had a skin (Dijkstra, 2005). Apparently, deodorising oil can drastically reduce its stability and shelf life and convert it from edible oil to varnish.

This deodorisation experiment was carried out quite some time ago and at the time, we were not in a position to analyse the deodorisate. Since then, analytical chemistry has become even more powerful and analysing this particular deodorisate might well reveal the existence of highly effective antioxidants ${ }^{4}$. Instead of worrying about the lack of stability of vegetable oil and evaluating all kinds of preferably 'natural' antioxidants, we should investigate why this oil is so remarkably stable.

Perhaps we could then also solve the problem of flavour reversion, an oxidation process that leads to a beany or fishy taste in soya bean oil. It is not known which compounds are oxidised and cause this poor taste. Because the offtaste can become fishy, the phospholipids are blamed since they contain amino groups. Unsaponifiables have also been blamed since their removal reduced the flavour reversion and adding them to oil can induce reversion. On the other hand, flavour reversion is not that much of a problem in Europe; yet another intriguing question that has not been satisfactorily answered.

\section{Saponification/hydrolysis during refining}

In the batch alkali refining process, the contact time between the caustic soda and the oil can be

\footnotetext{
${ }^{4}$ This footnote is not quite a "note added in proof" but when the manuscript of this article was about to be submitted, I received the November issue of the I Am Oil Chem Soc that contains an article (WinklerMoser and Vaughn, 2009) describing how volatile compounds had been removed from distillers dried grain oil by applying a very high vacuum and how the distillate could act as stabiliser. I asked the authors if they had observed any skin formation but have not yet received a reply.
}

quite long and this could lead to some saponification. Accordingly, several analytical methods have been developed to determine the extent of this saponification. Amongst these methods, the one developed by Naudet et al. (1953) may well be the most reliable provided saponification in the soapstock sample is prevented. In the literature, various authors report saponification during alkali refining and a study of the effect of process variables on saponification (Naudet et al., 1957) reports saponification losses of up to almost $1 \%$ of the oil.

For the continuous neutralisation process, it is assumed that the saponification is less severe since the time of contact between the lye and the oil is much shorter. Saponification is still mentioned in the literature and claimed to be less when using soda ash than when using caustic soda (Kaufmann and Mukherjee, 1965).

During steam refining, neutral oil can in theory also be lost by hydrolysis and several authors have studied this phenomenon. It was concluded to be unimportant at temperatures below $180^{\circ} \mathrm{C}$ (Szabó Sarkadi, 1959); in an industrial trial, oil loss by hydrolysis at an unspecified temperature amounted to only $0.05 \%$ (Kehse, 1963); it was found to be proportional to the amount of stripping steam and using $8 \%$ steam at a temperature of $220{ }^{\circ} \mathrm{C}$ led to an oil loss by hydrolysis of $0.15 \%$ (Jeberg, 1979); in a laboratory deodoriser, the loss was determined at only $0.05 \%$ at $260{ }^{\circ} \mathrm{C}$ (Deffense, 1995).

So what happens during industrial deodorisation or physical refining conditions is not quite clear. Accordingly, I would like to suggest a simple industrial experiment that will easily quantify the loss by saponification or hydrolysis. This experiment involves the neutralisation of a mixture of crude or degummed coconut oil still containing free fatty acids and neutral palm oil and taking samples of the resulting soapstock or distillate. Care must be taken that no further saponification takes place in the soapstock sample by cooling or acidifying this sample. If then the fatty acid composition of this sample is determined, the extent to which this deviates from the fatty acid composition of coconut oil allows the oil loss by saponification or hydrolysis to be quantified quite accurately.

Disposal of the neutral oil mixture is quite straightforward. Hydrogenating and interesterifying this mixture leads to a hardstock that can be used to produce a trans-free margarine or shortening (Delfosse, 1971; Fondu and Willems, 1972). In fact, such a hardstock is produced and sold under the name of PK3 by the Cargill plant in Harburg, Germany, which plant is therefore ideally suited to carry out the experiment suggested above. I hope that this experiment will be carried out and that its results will be reported.

\section{Remaining questions concerning the interesterification process}

In 1960, Baltes suggested a reaction mechanism for the base-catalysed ester interchange reaction between triglycerides (Baltes, 1960). This mechanism assumed a glycerolate anion to be the catalytically active intermediate. However, this mechanism did not explain why the amount of soaps formed when the catalysts is inactivated with water is equivalent to the amount of catalyst used (Kellens, 2000). It did not explain either how any free methanol present in the reaction mixture would be converted to fatty acid methyl esters (Eckey, 1948), why the fatty acids present in the triglycerides must have an $\alpha$-hydrogen to react (Liu, 2004) nor how molecules like acetone accelerate the reaction (Muller and Kock, 1974).

By suggesting another mechanism (Dijkstra et al., 2005) that assumes an enolate anion to be the catalytically active intermediate rather than the glycerolate anion, I could provide answers to the above questions but even so, there are other still questions waiting for an answer. It is for instance not clear what role the positive counter ion plays. According to Baltes (1960) the catalytic activity decreases in the order $\mathrm{K}>\mathrm{Na}>\mathrm{Li}>\mathrm{Mg}>\mathrm{Zn}$ but he provides no experimental evidence to support this statement. It is therefore not clear to what extent the high catalytic activity of the sodium/potassium alloy as used during the low-temperature directed interesterification (De Lathauwer et al., 1980) is due to its easy dispersibility or the presence of potassium. Accordingly, potential savings, if any, have never been quantified let alone realised.

It is well known that "activation" of the catalyst (the formation of the active intermediate from its precursor such as sodium methanolate or alkali metals) leads to colour formation which according to Braun (1960) "is probably due to the sodium glyceride compound believed to be 
the true catalyst". Subsequent literature (Liu and Lampert, 1999) states: "The color substance is very likely involved in the mechanism of interesterification although its identity is still unknown." It is also not known if the colour originates from triglycerides or nontriglyceride compounds. This could be established by reacting a catalyst precursor with a synthetic triglyceride but as far as I am aware, this has never been done.

The current industrial interesterification process employs $0.05 \%$ by weight of sodium methanolate, which amount ensures complete randomisation in a few minutes at temperatures of around 70 to $90^{\circ} \mathrm{C}$. In his doctoral thesis, Naudet (1947) used $1 \%$ at $205^{\circ} \mathrm{C}$ and it took him more than five hours to reach equilibrium. Apparently, the intermediate that is catalytically active at temperatures below $100^{\circ} \mathrm{C}$ loses its activity on heating. I suggested (Dijkstra et al., 2005) that this is because it reacts to form a $\beta$-keto ester, which no longer acts as interesterification catalyst. On the other hand, it is possible to carry out interesterification reactions at elevated temperatures with a catalyst obtained by dehydrating a solution of an alkali metal hydroxide in glycerol (Keulemans and Smits, 1986); what mechanism this leads to is not known.

Just heating triglycerides also leads to interesterification, as observed during the deodorisation of palm oil. However, it is not known if this ester interchange is within triglycerides (intra-esterification) or between triglycerides (inter-esterification). The reaction rate was found to depend strongly on the temperature (Willems and Padley, 1985) but the mechanism is not known. Is it acid-catalysed? If so, it would be more pronounced during physical refining than during deodorisation, which is quite relevant for palm oil to be used in confectionery applications.

\section{Miscellaneous questions}

The questions I have discussed so far could be grouped under distinct headings. During my presentation, I discussed several other questions that I will list below.

\section{Press effect during bleaching}

When oil has been treated with bleaching earth and a sample of the suspension is centrifuged, its oil colour is higher than that of the filtrate. Why? Could it be that the adsorption of the colour compounds in the dilute suspension had not yet reached equilibrium and that reaching equilibrium is facilitated in the filter cake where the bleaching earth concentration is much higher? Knowing the reason behind the press effect might lead to savings on bleaching earth.

\section{Wet bleaching}

After hydrogenation, the nickel catalyst is removed by filtration and then, residual nickel is removed during the "post-bleaching" step. Adding some water during this step greatly facilitates this removal (Kopp et al., 1989). Why would that be? In what form is the residual nickel present? Nickel soaps or nickel metal particles? How does the water interact with these nickel species?

Wet bleaching is also claimed to improve the removal of colouring compounds and especially lower the phosphorus content of the oil (Zschau, 1987). Is the reason thermodynamic in that water shifts the position of the adsorption equilibrium? Is the reason kinetic in that water increases the rate at which the various compounds are adsorbed? Or is this just another myth? Understanding what happens is desirable since it might lead to process improvements and hopefully savings.

\section{Colour fixation}

Normally, oils get lighter in colour on deodorisation because of thermal breakdown of colouring compounds like carotenes; this is called heat bleaching. It can also happen that oils get darker on deodorisation: colour fixation. What is the chemistry of colour fixation? Do phenolic compounds play a role? Could their condensation reactions be suppressed by maintaining acidity? Could their prior removal by an alkaline wash prevent colour fixation? Is there one cause or are there several? Lots of questions but sadly enough, no answers.

\section{Crystallisation memory}

During dry fractionation, all of us dutifully heat the oil to be fractionated to well above its melting point to "erase its crystal memory". What happens if we don't? Has this ever been reported in print? Does this so-called crystal memory really exist? And if it does, could we use it to promote the formation of a more uniform crystal mass with improved filtration characteristics?

\section{Secondary nucleation}

To make sure we obtain such a uniform crystal mass, we certainly should avoid secondary nucleation but what causes this phenomenon? Agitation has been mentioned (Timms, 1997) and since the linear speed of agitators increases with the size of the crystalliser, this could explain why the dry fractionation process is so difficult to scale up. It could also explain why crystallisers that have been fitted with agitators "each point of which moves with substantially the same speed" (Homann, 1996; Weber et al., 1998; Kellens and Hendrix, 2007) appear to suppress this secondary nucleation.

Of course there are many more unanswered questions relating to edible oil processing but I have limited my choice to the above, since in the limited time allotted for my address, I also wanted to highlight:

\section{The importance of the scientific literature}

This importance cannot be overemphasized since i.a. it provides us with analytical methods and shows us how our understanding gradually increased. A proper investigation of the literature - and this includes the patent literature - can prevent duplication of effort and at the same time provide us with ideas on how to improve our processes. It not only raises questions like the above, but also suggests solutions. Because of its importance, I can get quite annoyed when I come across sub-standard articles (Dijkstra, 2009). As I will illustrate below, there is certainly room for improvement and in my opinion, maintaining and preferably increasing the standard of the scientific literature in our sector can only result from a joint effort involving authors, reviewers, editors and also readers.

Take for instance the recent article by Stanisavljević et al. (2009). In this article, the authors describe several techniques for isolating oil from tobacco seed. These techniques comprise cold pressing and also direct ultrasonic extraction (DUE) using several power ratings. When reporting the fatty acid compositions of the various extracts, they note an increased saturated fatty acid content for the DUE oils and especially a decrease in polyunsaturated fatty acid content as illustrated in table 4.

When discussing these results, they refer to three articles that also describe ultrasound assisted oil extraction and report similar decreases in polyunsaturated fatty acid content which their authors attribute to oxidation. However, Stanisavljević et al. also quote an article that reports hydrogen being generated during sonication of hydrocarbons and so they conclude that the increase in saturated fatty acids is likely to be due to hydrogenation of unsaturated fatty acids.

This conclusion is not warranted because the palmitic acid formed during sonication requires palmitoleic acid as precursor and this is 
Table 4. Fatty acid compositions of oils extracted by different methods (Adapted from Stanisavljević et al. (2009)).

\begin{tabular}{|lcccc|}
\hline $\begin{array}{l}\text { Extraction } \\
\text { technique }\end{array}$ & $\begin{array}{l}\text { Cold } \\
\text { pressing }\end{array}$ & $\begin{array}{l}\text { Direct ultrasonic extraction } \\
\text { (DUE) }\end{array}$ & \\
\hline Power $(\mathrm{W})$ & n.a. & 5 & 10 & 50 \\
\hline C16:0 & 9.10 & 10.71 & 12.23 & 13.99 \\
\hline C18:0 & 3.27 & 3.49 & 4.33 & 4.91 \\
\hline C18:1 & 13.74 & 13.02 & 15.09 & 16.66 \\
\hline C18:2 & 71.01 & 70.19 & 63.95 & 58.03 \\
\hline
\end{tabular}

not present in the cold pressed oil. In fact, the observed increase in palmitic acid is an artefact of the GC analysis in which the total fatty acid content is set at $100 \%$; the palmitic acid content of the oil did not increase at all. So if in a sample the polyunsaturated fatty acid content decreases by oxidation, its saturated fatty acid content is automatically increased to maintain a sum of $100 \%$ despite the fact that some material does not elute.

What the authors should have done is to include an internal standard like tri-C17. Then they would have noted that the saturated fatty acid content did not increase but that the sum fell below $100 \%$. When preparing the slide pointing out the cause of this apparent anomaly, I likened this to people reporting an increase in saturated fatty acid content of frying oils during usage and lo and behold, an article on avoiding deterioration of frying oils (Aladedunye and Przybylski, 2009) was published in the September issue of the European Journal of Lipid Science and Technology making exactly that mistake. So I mentioned this article during my oral presentation.

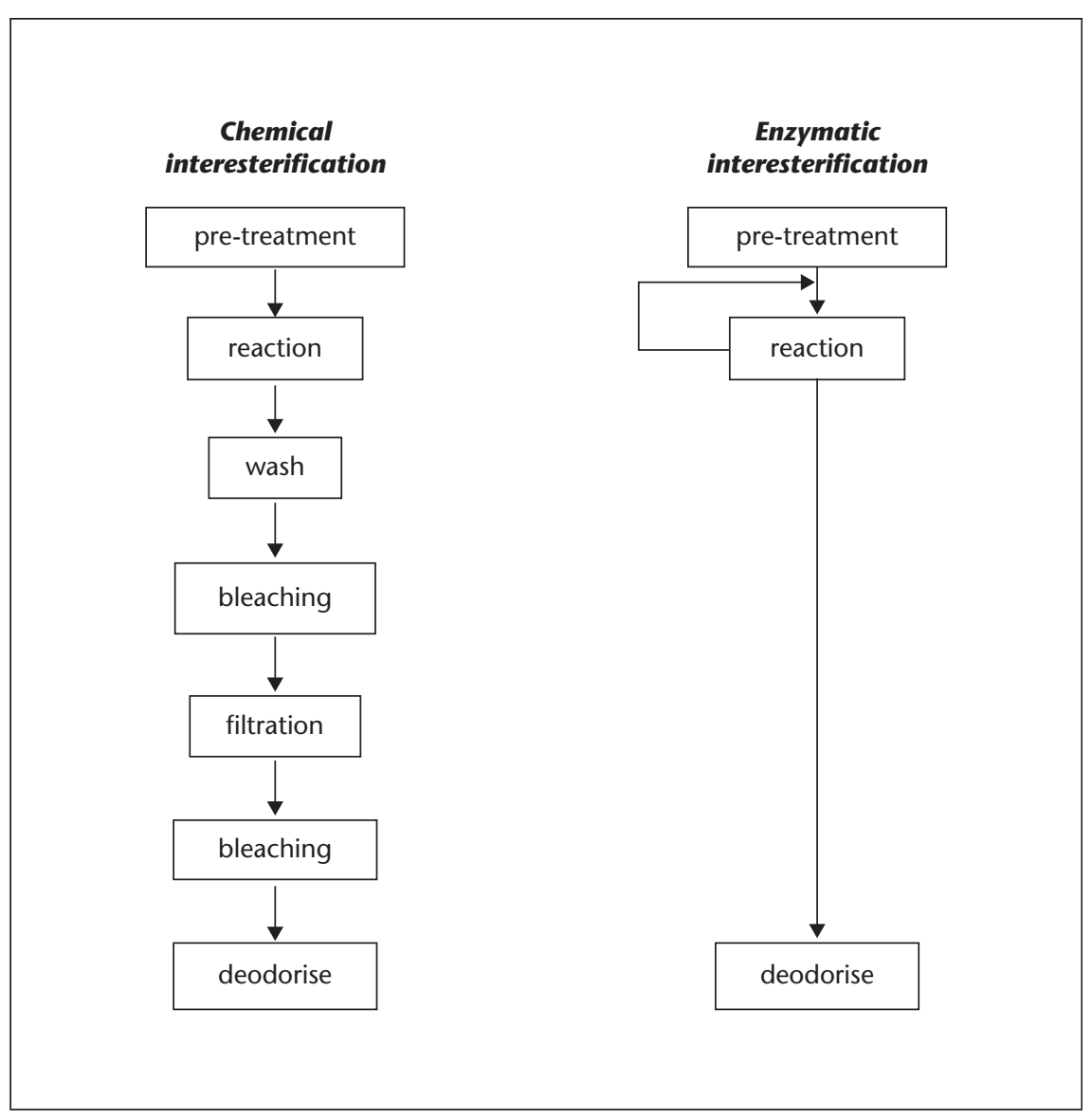

Figure 3. Comparison of process steps according to Holm and Cowan (2008).
I also mentioned an article (Ramli et al., 2009) about the production of a low cloud point palm olein I had also commented upon in my recent review (Dijkstra, 2009b); since this comment has been submitted as a Letter to the Editor of the Journal of the American Oil Chemists' Society (in press) I will not discuss it here. On the other hand, there is an article (Holm and Cowan, 2008) that I did not mention during my presentation but discussed in my review (Dijkstra, 2009b) as an example of an otherwise excellent article that sadly enough was biased and even misleading for commercial reasons. I also pointed out the danger that: "when these biased statements are repeated often enough, they start to lead a life of their own and tend to be no longer questioned." And this is exactly what happened. In a subsequent review article (Schörken and Kempers, 2009) the figure 3 consider to be biased was copied without comment.

This figure makes a comparison between the chemical interesterification and the enzymatic interesterification and I have reproduced it below as figure 3 ; I omitted the textual comments because I consider these to be misleading. The flow diagrams in figure 4 (Dijkstra, 2009a) also compare the chemical interesterification with the enzymatic process but they are biased in the other direction. Whereas figure 3 is biased in favour of the enzymatic process by creating the impression that it comprises far fewer steps than the chemical process, figure 4 does just the opposite by combining steps from the chemical process into a single posttreatment step and expanding the pretreatment of the enzymatic process.

What to do about such mishaps? Editors and reviewers should of course prevent such manuscripts from being published but what to do when a manuscript slips through the net and the readership is misinformed? At the moment, sending a letter to the editor is the only way to redress the situation but in practice, this is quite cumbersome and few readers will bother. Therefore, I think that a website forum could provide the answer to the above questions. In addition it would allow users to put questions to a wide and knowledgeable audience, enable people to share experience or make suggestions.

Such a forum requires some organisation. There should preferably be a single English language forum dealing with edible oils and fats, which requires some coordination between various national learned societies. Nonmembers of these societies should be allowed to register as a forum user and be notified each time a contribution is made and this requires an editor who also ensures that it does not become overtly commercial or libellous. 


\section{Chemical interesterification}

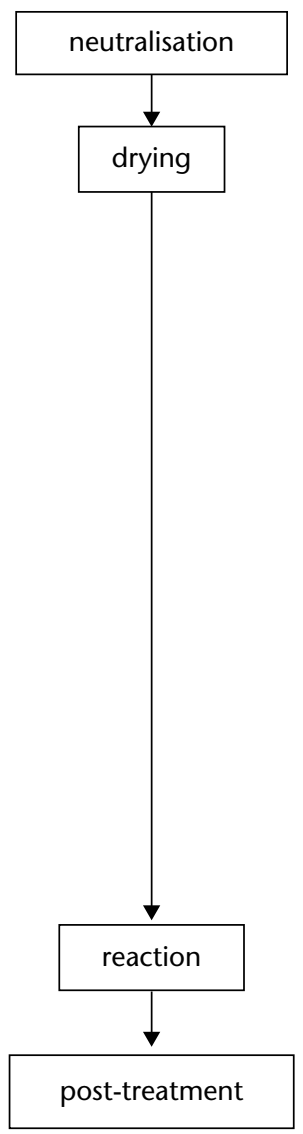

Enzymatic interesterification

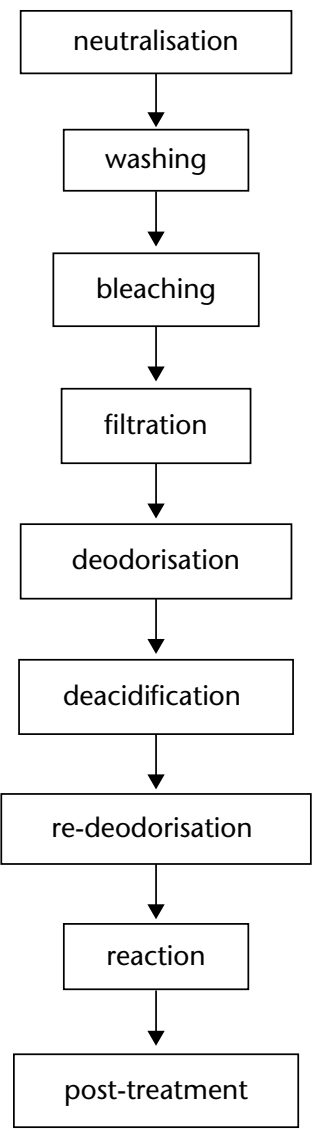

Figure 4. Comparison of process steps according to Dijkstra (2009a).

\section{REFERENCES}

Aladedunye FA, Przybylski R. Protecting oil during frying. Eur / Lipid Sci Technol 2009; 111: 893-901.

Baltes J. Reaktionsmechanismus und Kinetik der Umesterung von Fetten. Die Nahrung 1960; 4: 1-16.

Braun WQ. Interesterification of edible fats. I Am Oil Chem Soc 1960; 37: 598-601.

Cleenewerck B, Dijkstra AJ. The total degumming process - theory and industrial application in refining and hydrogenation. Fat Sci Technol 1992; 94: 317-22.

Dahlén JÅH. The Super Expro process. OCL 1998; 5: 360-3.

Dahlén JÅH. Process of producing glyceride oil having a low content of non-hydratable phosphatides, US Patent 6,103,918, assigned to Karlshamns Crushing \& Feed $A B, 2000$.
De Lathauwer R, Van Opstal M, Dijkstra AJ. Process for the directed interesterification of a triglyceride oil or oil mixture, European Patent 0009 207, assigned to N.V. Vandemoortele International, 1980.

Deffense EMJ. Usage of steam in physical refining. Oils \& Fats International 1995; 11: 24-8.

Deffense EMJ. From organic chemistry to fat and oil chemistry. OCL 2009; 16: 14-24.

Delfosse JKF. Margarine fat composition, British Patent 1244 868, assigned to Unilever, 1971.

Desnuelle P, Molines ], Bonjour S. Traitement thermique des graines oléagineuses et teneur en lécithine des huiles. Oléagineux 1951; 6: 264-7.

Dijkstra Al, Van Opstal M. The Total Degumming Process. J Am Oil Chem Soc 1989; 66: 1002-9.

Dijkstra AJ, Maes PJ, Meert D, Meeussen WLJ. Interpreting the oil stability index. OCL 1996; 3: 378-86.
Dijkstra AJ. No solution yet to the linolenic acid mystery. Inform 2005; 16: 283.

Dijkstra AJ, Tőke ER, Kolonits P, Recseg K, Kővári K, Poppe $\mathrm{L}$. The base-catalyzed, low temperature interesterification mechanism revisited. Eur / Lipid Sci Technol 2005; 107: 912-21.

Dijkstra AJ. Interesterification revisited. Alton E Bailey Award Address presented at the $100^{\text {th }}$ AOCS Annual Meeting \& Expo, Orlando, 2009a.

Dijkstra AJ. Recent developments in edible oil processing. Eur J Lipid Sci Technol 2009b; 111: 857-64.

Eckey EW. Process for treating fats and fatty oils, US Patent 2,442,531, assigned to The Procter \& Gamble Company, 1948

Fondu MPV, Willems MAG. Margarine fat containing randomized fat component, US Patent 3,634,100, assigned to Unilever, 1972

Frankel EN. Lipid oxidation. Bridgewater, UK: The Oily Press, 2005.

Holm HC, Cowan WD. The evolution of enzymatic interesterification in the oils and fats industry. Eur / $\mathrm{Li}$ pid Sci Technol 2008; 110: 679-91.

Homann T. Verfahren und Vorrichtung zum Kristallisieren, German Patent 19520675 A1, assigned to Krupp Kunststofftechnik GmbH, 1996.

Hvolby A. Removal of nonhydratable phospholipids from soybean oil. . Am Oil Chem Soc 1971; 48: 503-9.

Jacob F. The Possible and the Actual. New York: Pantheon Books, 1982.

Jeberg BV. Methematical model for removal of fatty acids during deodorization. Paper presented at the 10th Scandinavian Symposium on Lipids, Nyborg, Denmark, 1979, D-159-D-164.

Kanamoto R, Wada $Y$, Miyajimi G, Kito M. Phospholipid-phospholipid interaction in soybean oil. J Am Oil Chem Soc 1981; 58: 1050-3.

Kaufmann HP, Mukherjee KD. Neuzeitliche Technologie der Fette und Fettprodukte CVIII: Die Raffination der Fette. Fette Seifen Anstrichm 1965; 67: 814-20.

Kehse W. Über das Verweilzeitspektrum und die Anwendung eines Fettsäure-Kondensators bei einem kontinuierlichen Desodorisierer. Fette Seifen Anstrichm 1963; 65: 217-21.

Kellens MJ. Oil modification processes. In: Hamm W, Hamilton RJ, eds. Edible Oil Processing. Sheffield: Sheffield Academic Press, 2000: 127-73.

Kellens MJ, Hendrix M. Crystallisers useful in fractionation process for oils and fats, European Patent 1818 088 A1, assigned to De Smet Engineering N.V., 2007.

Keulemans CNM, Smits G. Interesterification process and apparatus, US Patent 4,585,593, assigned to Unilever, 1986.

Kock M. Production of an edible oil from crude soy oil, US Patent 4,255,346, assigned to Akzo N.V., 1981

Kock M. Oilseed pretreatment in connection with physical refining. J Am Oil Chem Soc 1983; 60: 150A-154A. 
Kopp H-PJ, Lammers JG, Wolk JA van der, Groot WT de. Process for preparing refined oil, US Patent 4, 857,237, assigned to Unilever, 1989

Kővári K. Recent developments, new trends in seed crushing and oil refining. Oléagineux Corps Gras Lipides/OCL 2004; 11: 381-7.

Liu L. How is chemical interesterification initiated: Nucleophilic substitution or $\alpha$-proton abstraction? J Am Oil Chem Soc 2004; 81: 331-7.

Liu L, Lampert DS. Monitoring chemical interesterification. / Am Oil Chem Soc 1999; 76: 783-7.

Muller J], Kock T). Interesterification of glycerides in the presence of an aliphatic ketone, US Patent 3,809,709, assigned to Unilever, 1974

Naudet M, Desnuelle P, Locatelli R, Bonjour S. Étude analytique de la neutralisation alcaline des huiles II. Dosage des glycérides (huile neutre) dans les huiles brutes et neutralisées. Bull Mens ITERG 1953; 274-80.

Naudet M. Contribution à l'étude des migrations d'acyles entre triglycérides. PhD thesis, Université de Marseilles, France, 1947.
Naudet M, Bonjour S, Arlaud M, Desnuelle P. Étude analytique de la neutralisation alcaline des huiles VI. Influence de divers facteurs sur les pertes par saponification au cours de la neutralisation alcaline continue. Rev Fr Corps Gras 1957; 4: 142-8.

Penk G. Praktische Erfahrungen met dem AlconProcess. Fette Seifen Anstrichm 1985; 87: 499-506.

Ramli MR, Siew W-L, Cheah KY. Production of high oleic palm oils on a pilot scale. J Am Oil Chem Soc 2009; 86: 587-94.

Rittner $\mathrm{H}$. Conditioning of oil-bearing materials for solvent extraction by extrusion. I Am Oil Chem Soc 1984; 31: 1200-3.

Schörken U, Kempers P. Lipid biotechnology: Industrially relevant production processes. Eur J Lipid Sci Technol 2009; 111: 627-45.

Segers JC. Oil purification by adding hydratable phosphatides, US Patent 4,162,260, assigned to Unilever, 1979

Stanisavljević IT, Veličković DT, Todorović ZB, Lazić $\mathrm{ML}$, Veljković VB. Comparison of techniques for the extraction of tobacco seed oil. Eur / Lipid Sci Technol 2009; 111: 513-8.
Sullivan FE. Process for refining fatty oils, US Patent 4, 089,880, assigned to Sullivan Systems Inc., 1978

Szabó Sarkadi D. Hydrolysis during deodorization of fatty oils. Catalytic action of fatty acids. I Am Oil Chem Soc 1959; 36: 143-5.

Timms RE. Fractionation. In: Gunstone FD, Padley FB, eds. Lipid Technologies and Applications. New York: Marcel Dekker, 1997: 199-222.

Weber K, Homann T, Willner T. Fat crystallizers with stirring surfaces: theory and practice. Oléagineux Corps Gras Lipides/OCL 1998; 5: 381-4.

Willems MAG, Padley FB. Palm oil: Quality requirements from a customer's point of view. I Am Oil Chem Soc 1985; 62: 454-9.

Winkler-Moser JK, Vaughn SF. Antioxidant activity of phytochemicals from distillers dried grain oil. / Am Oil Chem Soc 2009; 86: 1073-82.

Zhang F, Köseoğlu SS, Rhee KC. Effects of expander process on the phospholipids in soybean oil. J Am Oil Chem Soc 1994; 71: 1145-8.

Zschau W. Bleaching - An optimization, 1987. 